\title{
TESTES SAG/AG, EM ESCALA PILOTO E BANCADA, PARA COMINUIÇÃO DE ITABIRITO*
}

\author{
Armando Fernandes da Veiga Rodrigues ${ }^{1}$ \\ Pedro Ferreira Pinto ${ }^{2}$ \\ Joaquim Donizetti Donda ${ }^{3}$ \\ Neymayer Pereira Lima 4 \\ Marco Tulio Santiago Ferreira 5 \\ Luís Marcelo Marques Tavares ${ }^{6}$ \\ Malcolm Powell
}

\section{Resumo}

Itabirito é um minério de fero encontrado no Brasil. As reservas futuras de Itabirito requerem moagem para atingir o grau de liberação necessário para concentração. Os circuitos convencionais de cominuição adotados em projetos de Itabirito consistem de três estágios de britagem seguido de moinhos de bolas. Estes circuitos demandam uma alta frequência de manutenção e uma grande área de construção. Por esta razão um estudo de bancada e piloto foi conduzido para entender a rota de cominuição de Itabirito utilizando moinhos autógenos (AG ou FAG) e semi-autógeno (SAG). Os testes piloto demonstraram que moinhos SAG e AG são apropriados para a cominuição de Itabirito.

Palavras-chave: Moagem; Itabirito; SAG; AG.

\section{PILOT AND BENCH SCALE TESTS OF SAG/AG MILLS FOR COMMINUTION OF ITABIRITE}

\section{Abstract}

Itabirite is an iron ore found in Brazil. The future Itabirite resources require grinding down to a fine size to liberate and concentrate. The conventional comminution circuits assumed in projects processing Itabirite consist of three stages of crushing followed by ball mills. These circuits require high demand for maintenance and large area of construction. Hence, was conducted bench-scale and pilot-scale tests to understand and to characterize the comminution potential of Itabirite ores using semiautogenous (SAG) and fully-autogenous (AG or FAG) grinding. The pilot tests demonstrated that $S A G$ and $A G$ technology work properly for the size reduction of Itabirite.

Keywords: Grinding; Itabirite; SAG; AG.

1 Engenheiro de Minas, candidato à M.Phil no JK Australia, Engenheiro Sênior, Vale, Desenvolvimento de Processos de Tratamento de Minério, Nova Lima, MG, Brasil.

2 Engenheiro Metalurgista, candidato à Mestre na USP, Engenheiro Pleno, Vale, Desenvolvimento de Processos de Tratamento de Minério, Nova Lima, MG, Brasil.

3 Engenheiro de Minas, Doutor, Gerente Técnico Sênior, Vale, Desenvolvimento de Processos de Tratamento de Minério, Nova Lima, MG, Brasil.

4 Engenheiro de Minas, Doutor, Engenheiro Master, Vale, Desenvolvimento de Processos de Tratamento de Minério, Nova Lima, MG, Brasil.

5 Engenheiro de Minas, Gerente de Área, Vale, Desenvolvimento de Processos de Tratamento de Minério, Nova Lima, MG, Brasil.

6 Engenheiro de Minas, Ph.D., Professor Associado, Programa de Engenharia Metalúrgica e de Materiais, COPPE, UFRJ, Rio de Janeiro, RJ, Brasil.

7 Bachelor of Science, Ph.D., Professor, Chair in Comminution, JKMRC, UQ, Australia.

* Contribuição técnica ao 44 Seminário de Redução de Minério de Ferro e Matérias-primas, 15은 Simpósio Brasileiro de Minério de Ferro e 2ํ Simpósio Brasileiro de Aglomeração de Minério de Ferro, 15 a 18 de setembro de 2014, Belo Horizonte, MG, Brasil. 


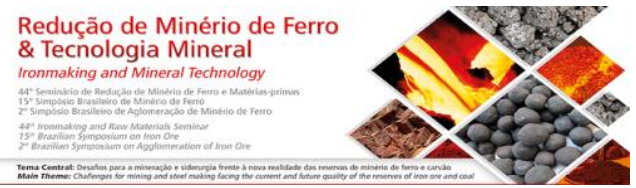

\section{INTRODUÇÃO}

Os minérios de ferro brasileiros estão mudando de alto teor com boa liberação na fração grossa, para baixo teor com liberação nas frações finas, requerendo moagem para atingir o grau de liberação necessário para concentração. Considerando as altas taxas de produção requeridas para os novos projetos, é importante assegurar a viabilidade econômica e energética de longo prazo. Os circuitos convencionais de cominuição adotados em projetos de Itabirito consistem de três estágios de britagem seguido de moinhos de bolas. Estes circuitos são caracterizados por um grande número de equipamentos os quais demandam manutenção e uma grande área de construção. Segundo Lima et. al. [4] a utilização de rota SAG apresenta significativa redução de CAPEX e OPEX para itabiritos com Wi operacional acima de 7,8 kWh/t.

Por esta razão um estudo em escala de bancada e piloto foi conduzido para entender a rota de cominuição de Itabirito utilizando moinhos autógenos (AG ou FAG) e semi-autógeno (SAG).

Um exemplo de simplificação é ilustrado na Figura 1, na qual são apresentados dois circuitos para produção de 30 milhões de toneladas de ROM (run-of-mine):

- Circuito denominado convencional o qual é constituído por dois estágios de peneiramento $(\mathrm{PN})$, três estágios de britagem (BR) e dois moinhos de bolas (MO).

- Circuito denominado SAB o qual é constituído de britagem primária, de um $\mathrm{SAG}$ e de dois moinhos de bolas (MO).

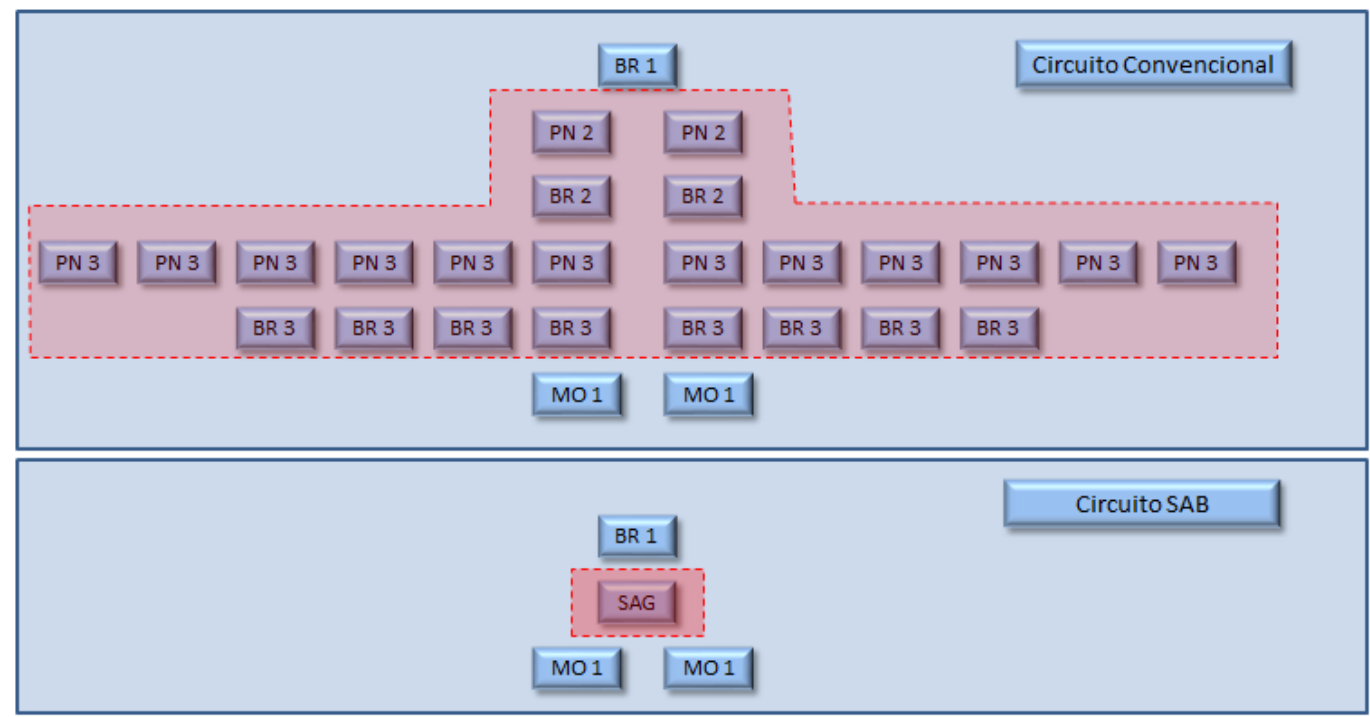

Figura 1 - Circuito convencional x SAB para um projeto de 30 Mtpa de ROM

\subsection{Teorias de Dimensionamento SAG/AG}

Existem basicamente três teorias que utilizam testes em escala de bancada para dimensionamento de moinhos SAG/AG:

- Teoria de Bond.

- SAG Power Index (SPI) - Desenvolvido por John Starkey.

- Drop Weight Test (DWT) - Desenvolvido pelo JKMRC.

Bond [1] introduziu o parâmetro denominado "work index" ou simplesmente Wi, o qual é o kW-hr por tonelada requerido para quebrar o minério de um tamanho infinito

* Contribuição técnica ao 44 Seminário de Redução de Minério de Ferro e Matérias-primas, 15 Simpósio Brasileiro de Minério de Ferro e 2ํ Simpósio Brasileiro de Aglomeração de Minério de Ferro, 15 a 18 de setembro de 2014, Belo Horizonte, MG, Brasil. 
até $\mathrm{P} 80=100$ micrometros. $\mathrm{O}$ Wi pode ser estimado através de um teste de bancada e através da Equação 1:

Onde:

$$
\mathrm{W}=10 \mathrm{Wi}\left(1 / \sqrt{\mathrm{P}_{80}}-1 / \sqrt{\mathrm{F}_{80}}\right)
$$

$\mathrm{W}=$ energia especifica requerida $(\mathrm{kWh} / \mathrm{t})$.

$\mathrm{Wi}=$ work index $(\mathrm{kWh} / \mathrm{t})$.

P80 $=$ malha na qual $80 \%$ do produto passa $(\mathrm{mm})$.

$\mathrm{F} 80=$ malha na qual $80 \%$ da alimentação passa $(\mathrm{mm})$.

A teoria de Bond, entretanto, tem limitações quando aplicada para predizer a resposta da moagem em um moinho de bolas posterior a um moinho SAG/AG. Isto pode ser visto através do artigo de Bond denominado "The Third Theory of Comminution" onde ele mostra que a inclinação média da curva de distribuição granulométrica da alimentação e produto, em um gráfico com escala log-log da \% passante versus tamanho é próximo de $/ 1 / \sqrt{2}$. Isto sugere que os as curvas de alimentação e produto deveriam ser paralelas para ser usada a teoria de Bond. Morrell et. al. [5] mostrou que em um circuito com SAG/AG seguido por moinho de bolas, as curvas de alimentação e produto do moinho de bolas não são paralelas (Figura 2).

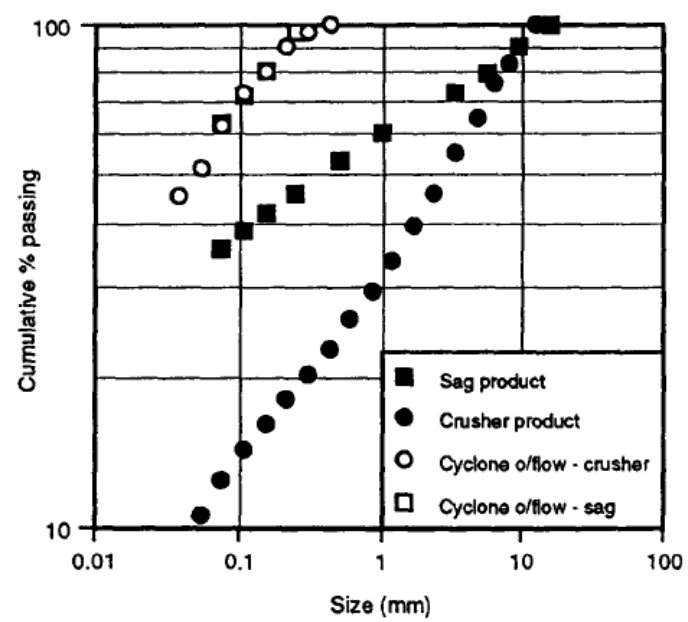

Figura 2 - Distribuição granulométrica de circuitos Britador/Moinho de bolas e SAG/Moinho de bolas [5].

Starkey et al. [7] propôs um teste (SPI) realizado em um moinho de diâmetro igual a $30,5 \mathrm{~cm}$ e comprimento igual a $10.2 \mathrm{~cm}$. Este teste requer $2 \mathrm{~kg}$ de amostra seca britada com $80 \%$ passante em $12,7 \mathrm{~mm}$. O teste é conduzido computando o tempo necessário para gerar um produto com $80 \%$ passante em $1,7 \mathrm{~mm}$. Após correlações com plantas industriais, Starkey desenvolveu uma equação para predizer a energia necessária para realizar o trabalho predeterminado (Equação 2):

$$
\mathrm{SAG} \mathrm{kWh} / \mathrm{t}=\mathrm{P}_{80}^{-0.33}(2.2+0.10 \mathrm{t})
$$

Onde:

$\mathrm{P} 80=$ malha na qual $80 \%$ da massa passa, $\mathrm{mm}$.

$\mathrm{t}=$ tempo de moagem, min.

O DWT, desenvolvido pelo Julius Kruttschnitt Mineral Research Centre (JKMRC), é um teste que avalia a resistência ao impacto do minério em função do tamanho da

* Contribuição técnica ao 44 Seminário de Redução de Minério de Ferro e Matérias-primas, 15 Simpósio Brasileiro de Minério de Ferro e 2ํ Simpósio Brasileiro de Aglomeração de Minério de Ferro, 15 a 18 de setembro de 2014, Belo Horizonte, MG, Brasil. 
partícula. Conceitualmente o teste consiste na aplicação de uma energia conhecida (através da queda de uma massa conhecida de uma determinada altura) em uma única partícula de determinado tamanho. Após o teste, as partículas fragmentadas são encaminhadas para avaliação da granulometria. A preparação das amostras para os ensaios consiste na britagem, seguida de classificação do produto nas faixas $63-53 \mathrm{~mm}, 45-37,5 \mathrm{~mm}, 31,5-26,5 \mathrm{~mm}, 22,4-19,0 \mathrm{~mm}, 16,0-13,2 \mathrm{~mm}$ para ensaios na célula de impacto.

Segundo Napier-Munn et. al. [6], a distribuição granulométrica dos fragmentos gerados são normalizadas e correlacionadas com a energia específica aplicada conforme a Equação 3.

$$
t_{10}=A\left(1-e^{-b \times E c s}\right)
$$

Onde:

t10: percentual passante na malha equivalente a $10 \%$ do tamanho original do fragmento

Ecs: energia específica aplicada na partícula $(\mathrm{kWh} / \mathrm{t})$

$A$ e b: parâmetros característicos do minério

A: fisicamente significa o valor máximo de t10

Axb: fisicamente significa a inclinação da curva quando o Ecs tende a zero (quanto menor mais competente é o minério).

\subsection{Fluxo de Polpa Máximo para Moinhos SAG/AG}

A figura a seguir ilustra as seções típicas em moinhos SAG/AG.

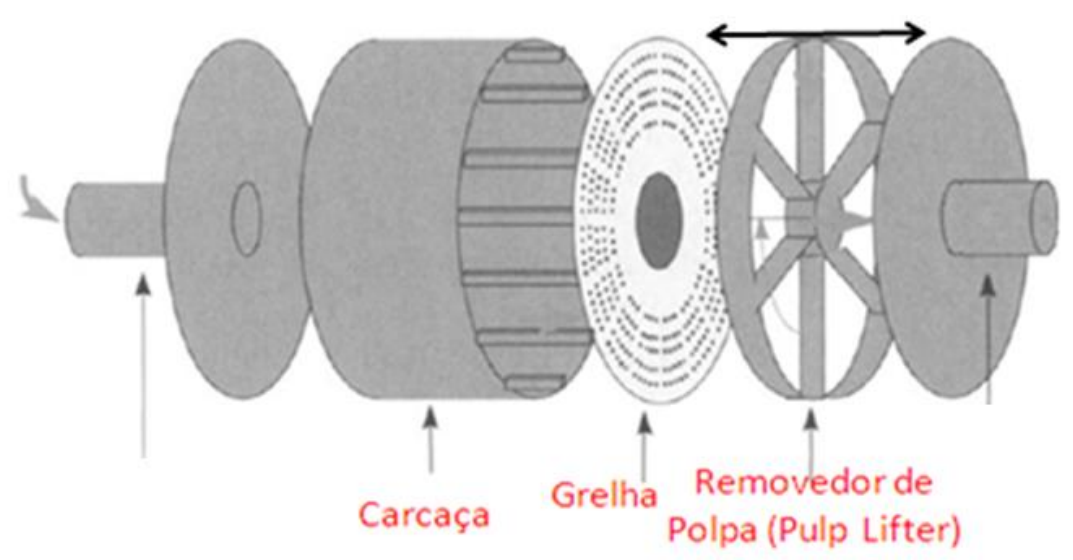

Figura 3 - Seções típicas de moinhos SAG/AG [3].

Nos moinhos SAG/AG a polpa deve passar pela grelha e depois ser removida pelos pulp lifters. Quando o fluxo de polpa é superior à capacidade de remoção do sistema grelha/pulp-lifter, ocorre o fenômeno denominado slurry pool (em tradução literal: piscina de polpa). A figura a seguir apresenta os comportamentos da carga/polpa mediante o fluxo de polpa. Quando ocorre slurry pool, a eficiência energética reduz, pois a energia será dissipada na piscina. Portanto este fenômeno dever ser evitado.

* Contribuição técnica ao 44 Seminário de Redução de Minério de Ferro e Matérias-primas, 15 Simpósio Brasileiro de Minério de Ferro e 2ํ Simpósio Brasileiro de Aglomeração de Minério de Ferro, 15 a 18 de setembro de 2014, Belo Horizonte, MG, Brasil. 

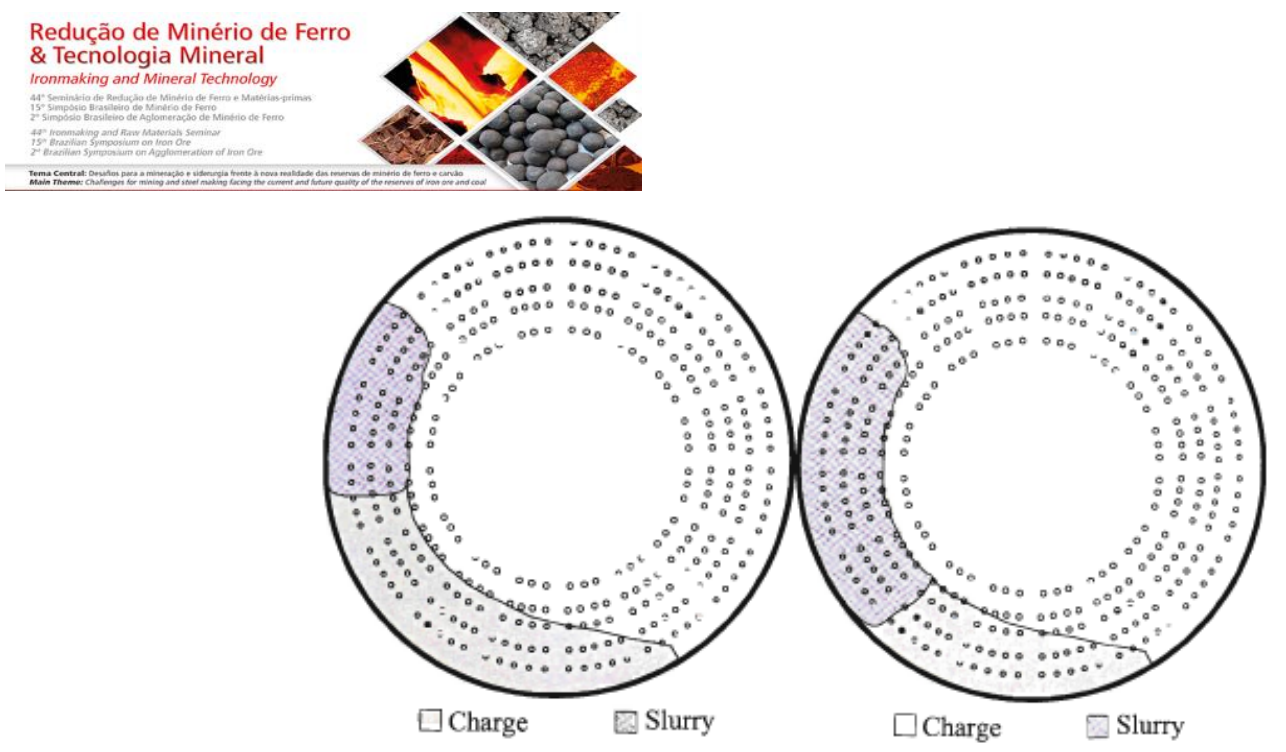

(a) Low flowrate

(b) Medium flowrate

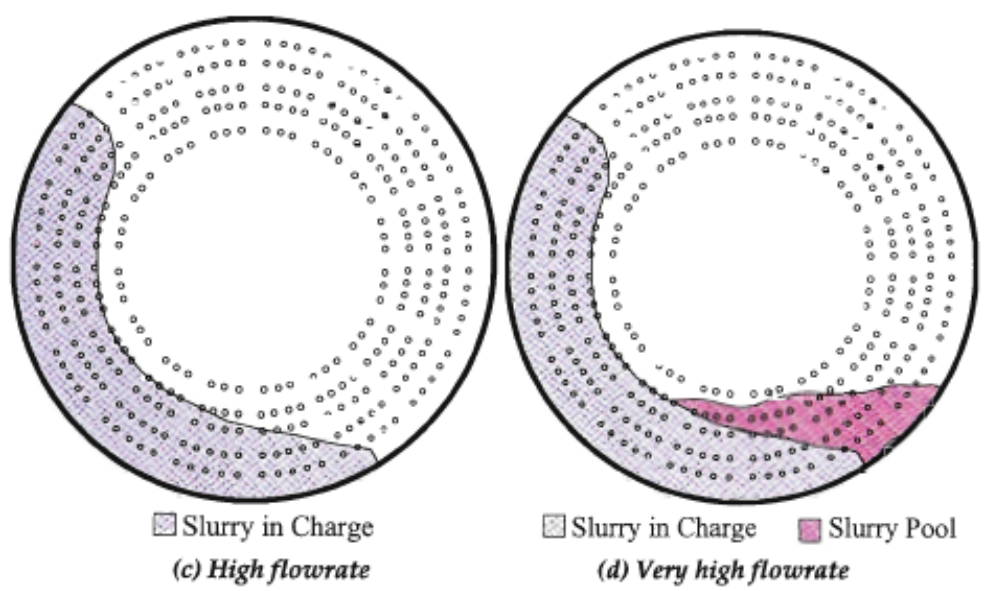

Figura 4 - Carga/polpa vs. fluxo de polpa [3].

Sanjeeva Latchireddi [3] propôs varias equações para predição do fluxo de polpa máximo antes da formação de piscina. Ele mostrou que o fluxo de polpa máximo é função do diâmetro do moinho, ou seja, quanto maior o diâmetro do moinho, mais polpa pode ser alimentada antes da formação de piscina.

\section{MATERIAIS E MÉTODOS}

Para o estudo piloto foram selecionadas amostras de cinco minas da Vale S.A.. Estas minas são:

- Cauê - localizada em Itabira, MG, Brasil.

- Conceição - localizada em Itabira, MG, Brasil.

- Pico (GAL - Galinheiro e SAP - Sapecado) - localizada em Itabirito, MG, Brasil.

- Jangada - localizada em Sarzedo, MG, Brasil.

As amostras foram classificadas como compactas (IC) ou friáveis (IF) de acordo com sua distribuição granulométrica.

\subsection{Testes Piloto}

Os minérios de Cauê e Conceição foram testados na planta piloto do CETEM, já os outros minérios foram testados na planta piloto do CIMM no Chile. Os moinhos

* Contribuição técnica ao 44 Seminário de Redução de Minério de Ferro e Matérias-primas, $15^{\circ}$ Simpósio Brasileiro de Minério de Ferro e $2^{\circ}$ Simpósio Brasileiro de Aglomeração de Minério de Ferro, 15 a 18 de setembro de 2014, Belo Horizonte, MG, Brasil. 
SAG/AG das duas plantas são idênticos, com Ø6' (1.83 m) x 2' (0.61 m). Foram testadas basicamente quatro rotas, as quais são ilustradas nas figuras a seguir.
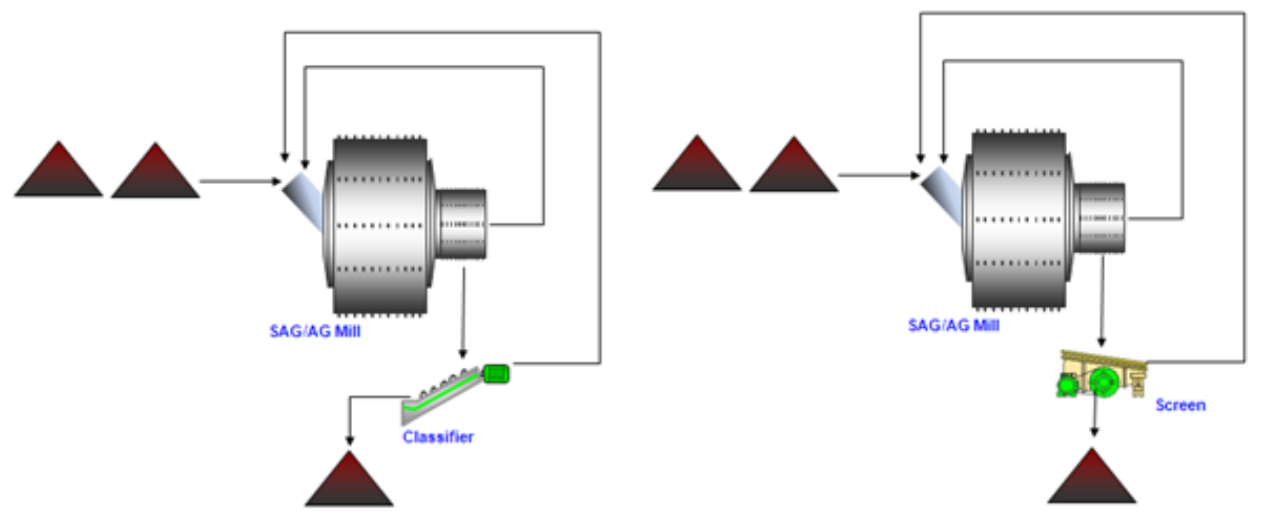

Figura 5 - Configurações usadas em testes com circuito fechado (Single Stage)
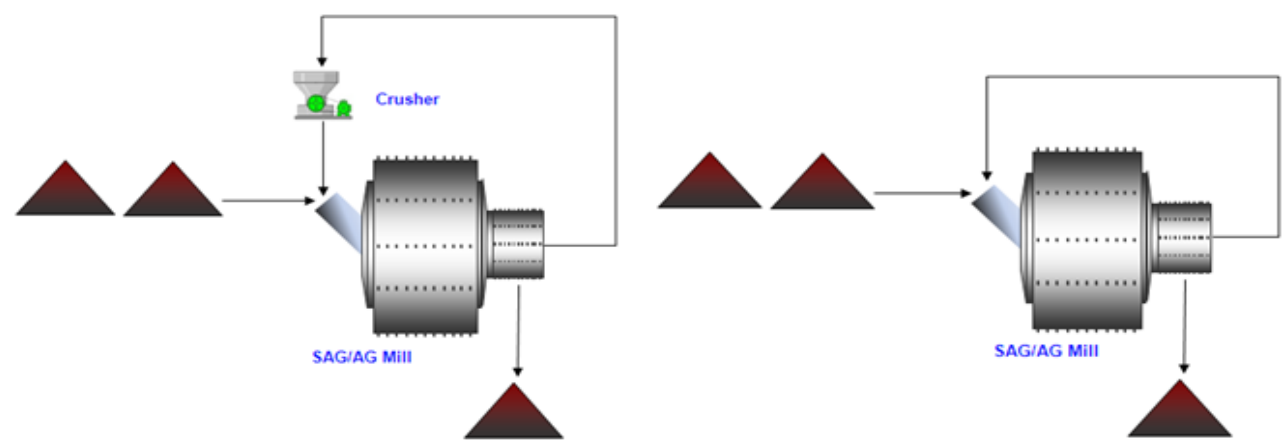

Figura 6 - Configurações usadas em testes com circuito aberto

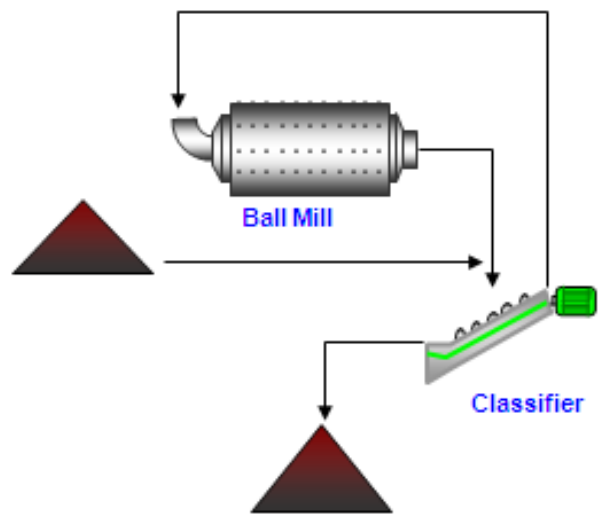

Figura 7- Configurações usadas em testes com moagem de bolas

Para os testes em Single Stage, o produto do teste já era produto final, porém para os testes em circuito aberto, em alguns testes o minério foi posteriormente enviado para o moinho de bolas, gerando então um produto final. O circuito SAG/AG aberto em conjunto com o moinho de bolas é denominado $S A B$ ou $S A B C$, onde o $C$ provém de Crusher (britador) o qual brita os pebbles (Figura 8).

* Contribuição técnica ao 44 Seminário de Redução de Minério de Ferro e Matérias-primas, $15^{\circ}$ Simpósio Brasileiro de Minério de Ferro e 2 Simpósio Brasileiro de Aglomeração de Minério de Ferro, 15 a 18 de setembro de 2014, Belo Horizonte, MG, Brasil. 

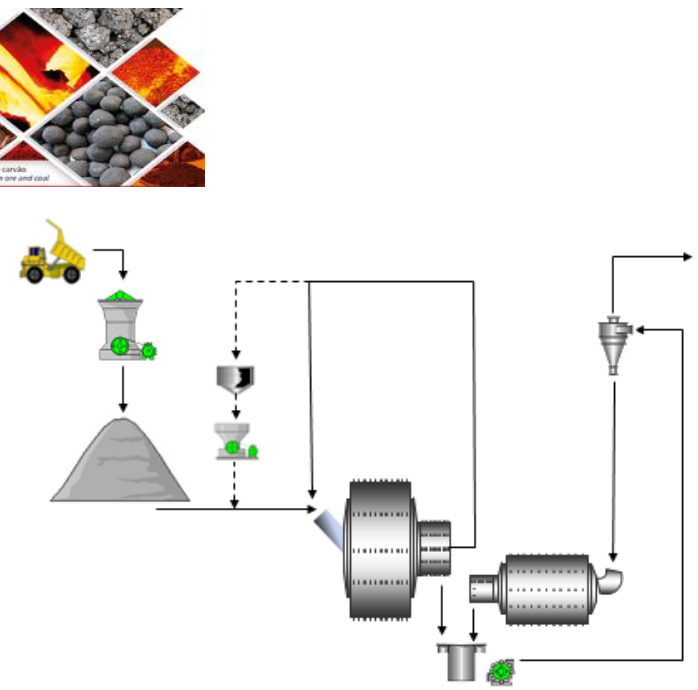

Figura 8 - Circuito industrial $S A B$ ou SABC

\subsection{Testes em Escala de Bancada}

Foi separada uma massa das amostras piloto dos minérios do Pico e Jangada para testes de DWT, moabilidade e abrasividade de Bond. Para se conhecer a variabilidade destes depósitos, foram coletadas 125 amostras de furos de sonda e realizados testes de DWT e Bond.

\section{RESULTADOS E DISCUSSÃO}

\subsection{Resultados dos Testes Piloto}

A Figura 9 apresenta a distribuição granulométrica das amostras piloto. Pode-se notar que as amostras de Conceição e Cauê apresentam distribuição granulométrica mais grossa, seguidas da amostra de Jangada.

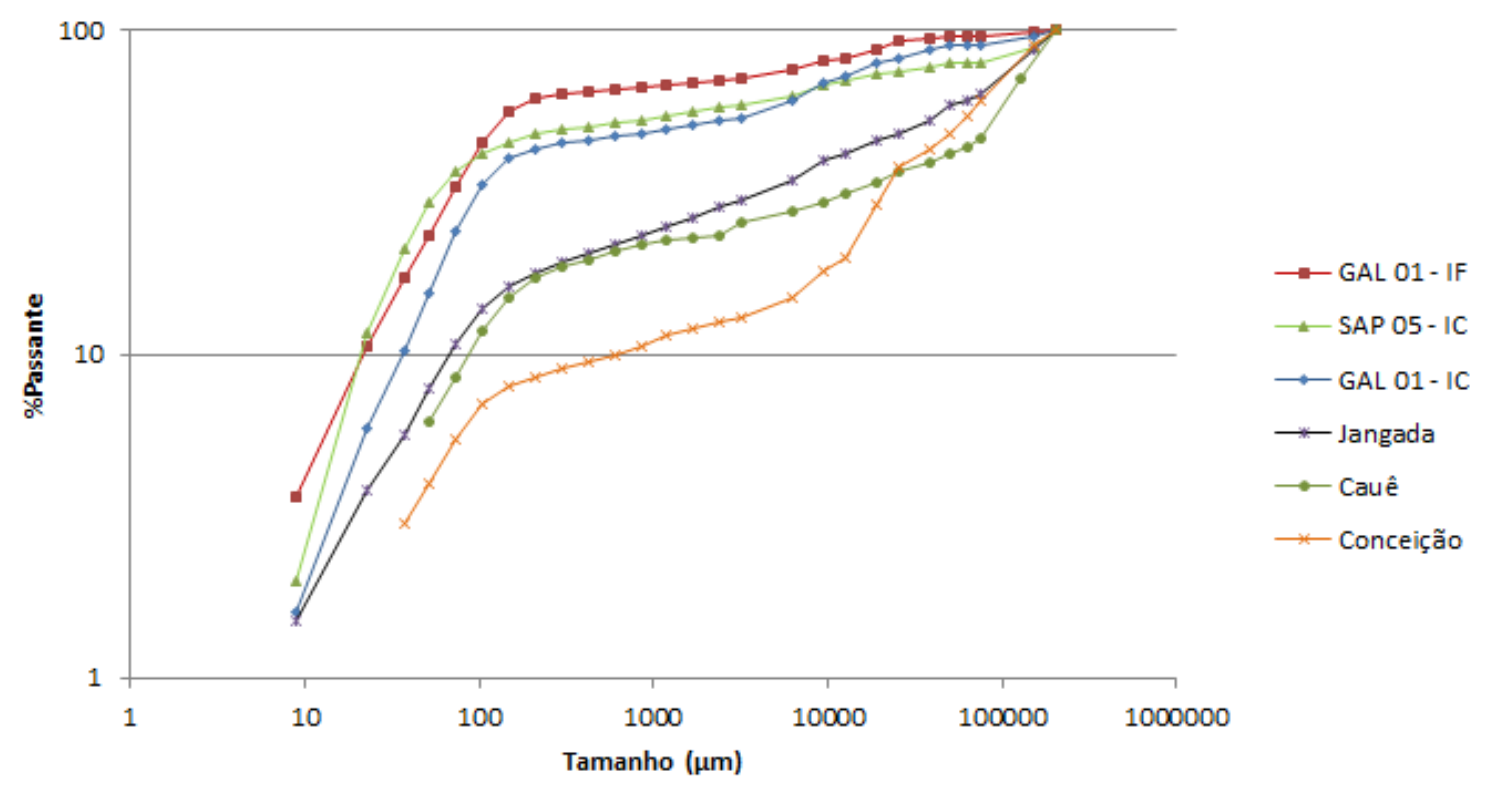

Figura 9 - Distribuição granulométrica das amostras dos testes piloto

A Tabela 1 apresenta os resultados dos testes piloto de SAG/AG em circuito aberto, vale ressaltar que esta tabela não apresenta nenhum resultado dos testes com moinhos de bolas. Já a Tabela 2 apresenta os resultados dos testes em circuito fechado (Single Stage)

* Contribuição técnica ao 44 Seminário de Redução de Minério de Ferro e Matérias-primas, $15^{\circ}$ Simpósio Brasileiro de Minério de Ferro e 2 Simpósio Brasileiro de Aglomeração de Minério de Ferro, 15 a 18 de setembro de 2014, Belo Horizonte, MG, Brasil. 
Tabela 1 - Resumo dos resultados dos testes piloto em circuito aberto

\begin{tabular}{cccc}
\hline Ano do Teste & Mina & Circuito Aberto & $\begin{array}{c}\mathrm{kWh} / \mathrm{t} \mathrm{p} / \mathrm{P} 58 \mathrm{em} \\
0,15 \mathrm{~mm}\end{array}$ \\
\hline 2006 & Conceição & SAG & 2,8 \\
2006 & Conceição & SAG + Britador & 2.4 \\
2012 & Pico & SAG & 1.3 \\
2012 & Pico & AG & 1.6 \\
\hline 2012 & Jangada & SAG & 8.9 \\
2012 & Jangada & SAG + Britador & 8.9 \\
\hline Tabela 2-Resumo dos resultados dos testes piloto em circuito fechado (Single Stage)
\end{tabular}

Bueno et. al. [2] consolidou em um artigo 134 testes piloto de SAG/AG, utilizando diferentes minérios. Neste artigo ele plota um gráfico de \% passante no produto versus energia especifica, então para o presente trabalho foi utilizado o gráfico de Bueno e inserido os dados dos testes com Itabirito (Figura 10). Através desta figura é possível notar que Itabirito está fora do range normal de energia especifica.

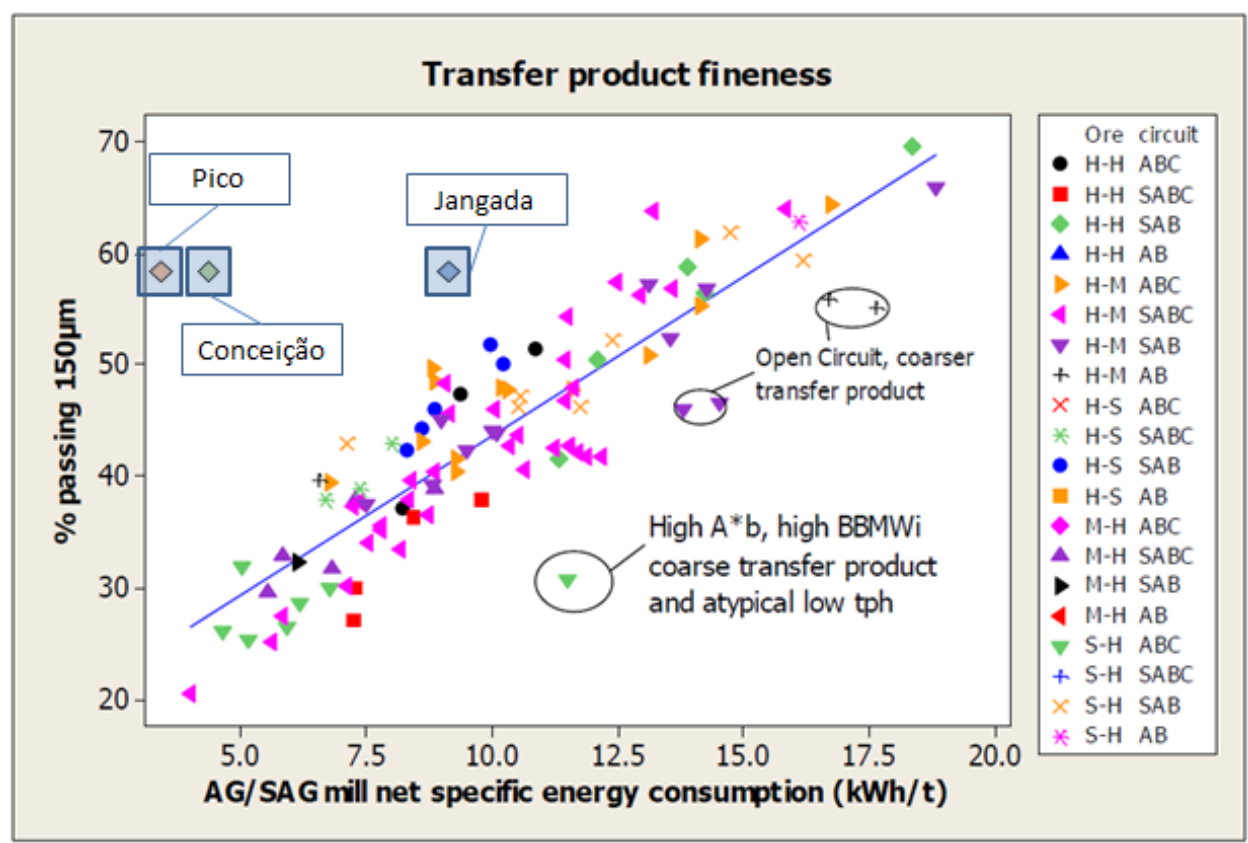

Figura 10 - Correlação entre energia especifica e \% passante no produto [2].

* Contribuição técnica ao $44^{\circ}$ Seminário de Redução de Minério de Ferro e Matérias-primas, 15은 Simpósio Brasileiro de Minério de Ferro e 2ํ Simpósio Brasileiro de Aglomeração de Minério de Ferro, 15 a 18 de setembro de 2014, Belo Horizonte, MG, Brasil. 
Bueno et. al. [2] também apresenta uma figura na qual é plotado o Wi de Bond versus Axb proveniente do DWT. Como foram realizados ensaios de Bond e DWT para os minérios do Pico e Jangada, esta figura foi utilizada para comparação entre minérios (Figura 11). Esta figura comprova novamente que Itabirito está fora do range normal de energia especifica.

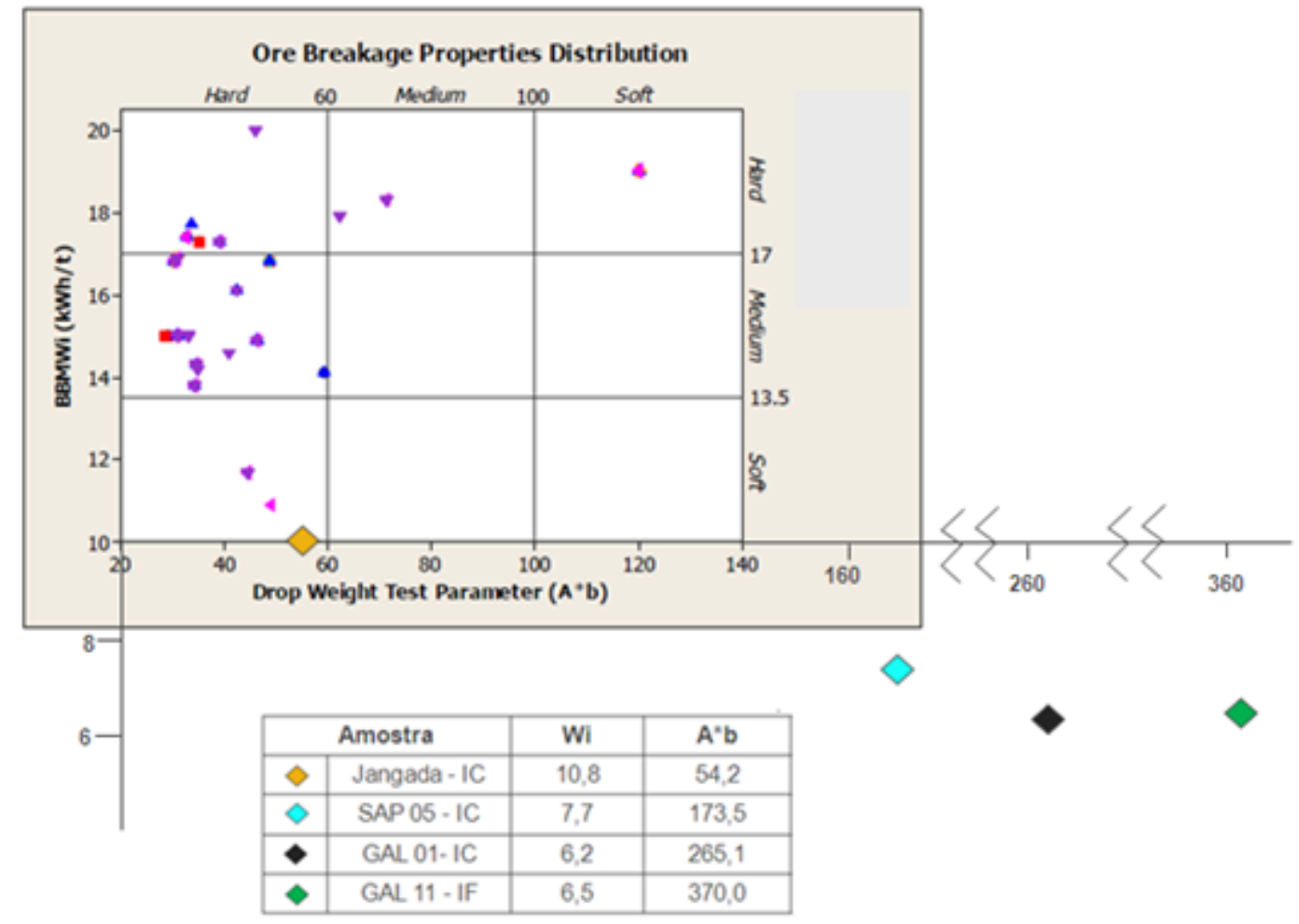

Figura 11 - Correlação entre Wi de Bond e Axb do DWT [2].

Com as amostras do Pico e Jangada, foram realizados 21 testes em escala piloto, de forma a se conhecer o desempenho da moagem SAG/AG variando as condições de trabalho, tais como: \% enchimento de bolas; circuito aberto e fechado; distribuição granulométrica; etc.. As figuras a seguir sumarizam os resultados dos testes com estas amostras
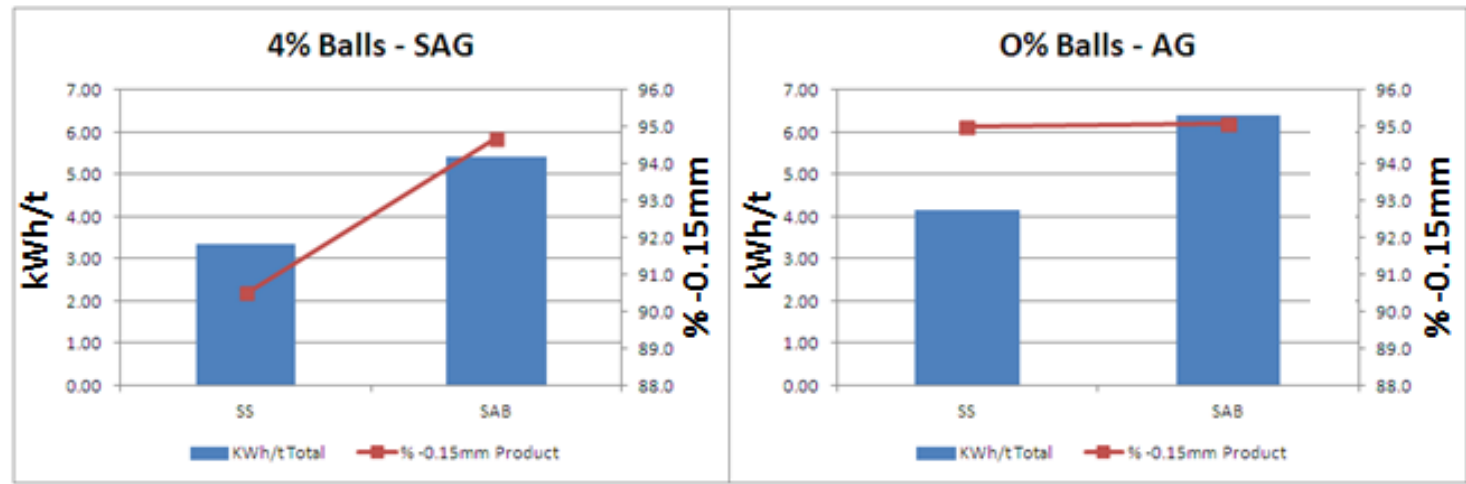

Figura 12 - SAG x FAG - GAL 01 - IC (Pico) - Resultados dos testes em Single Stage e SAB

* Contribuição técnica ao 44 Seminário de Redução de Minério de Ferro e Matérias-primas, $15^{\circ}$ Simpósio Brasileiro de Minério de Ferro e 2 Simpósio Brasileiro de Aglomeração de Minério de Ferro, 15 a 18 de setembro de 2014, Belo Horizonte, MG, Brasil. 

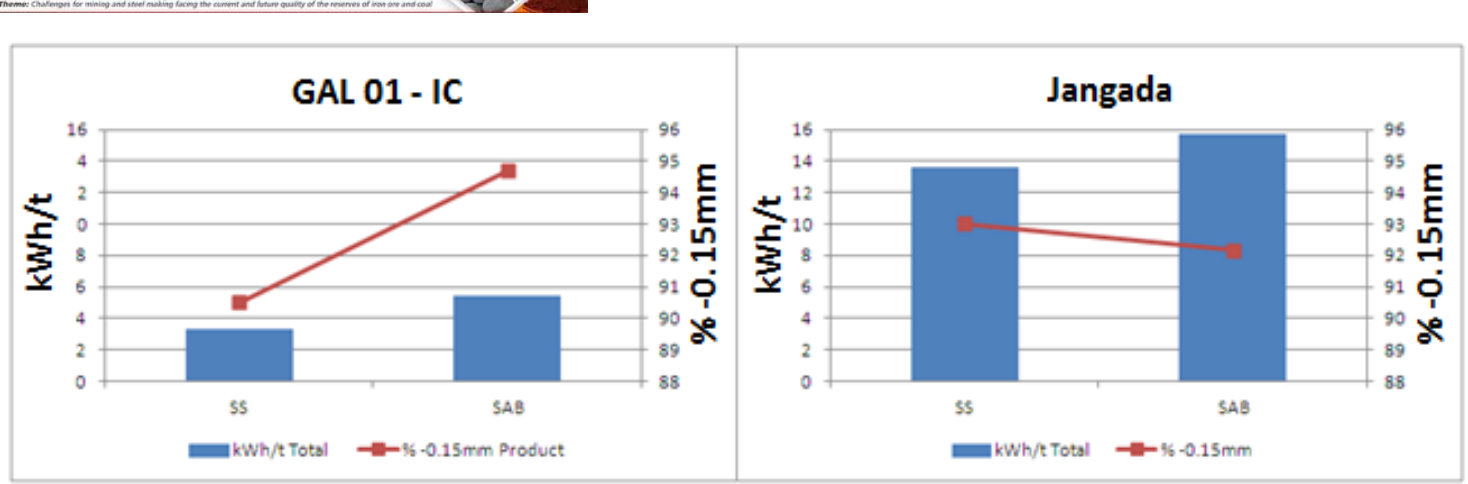

Figura 13 - Comparação entre amostras - Galinheiro (Pico) x Jangada - Resultados dos testes em Single Stage e SAB

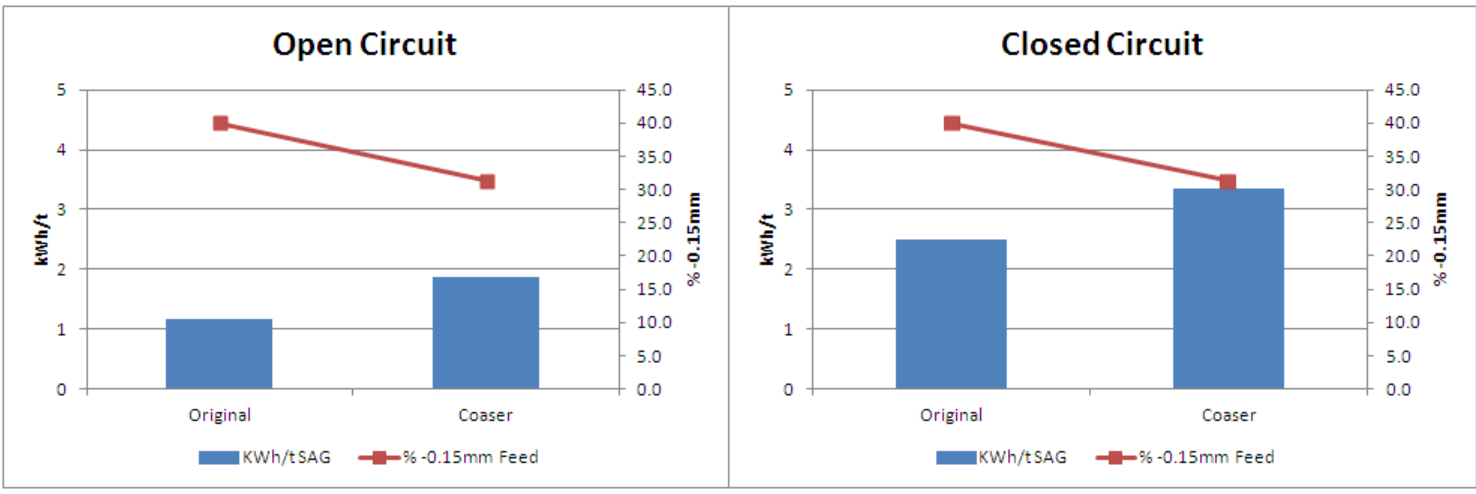

Figura 14 - Variação da granulometria (Original e Grossa) - GAL 01 - IC (Pico) - Resultados dos testes com o SAG

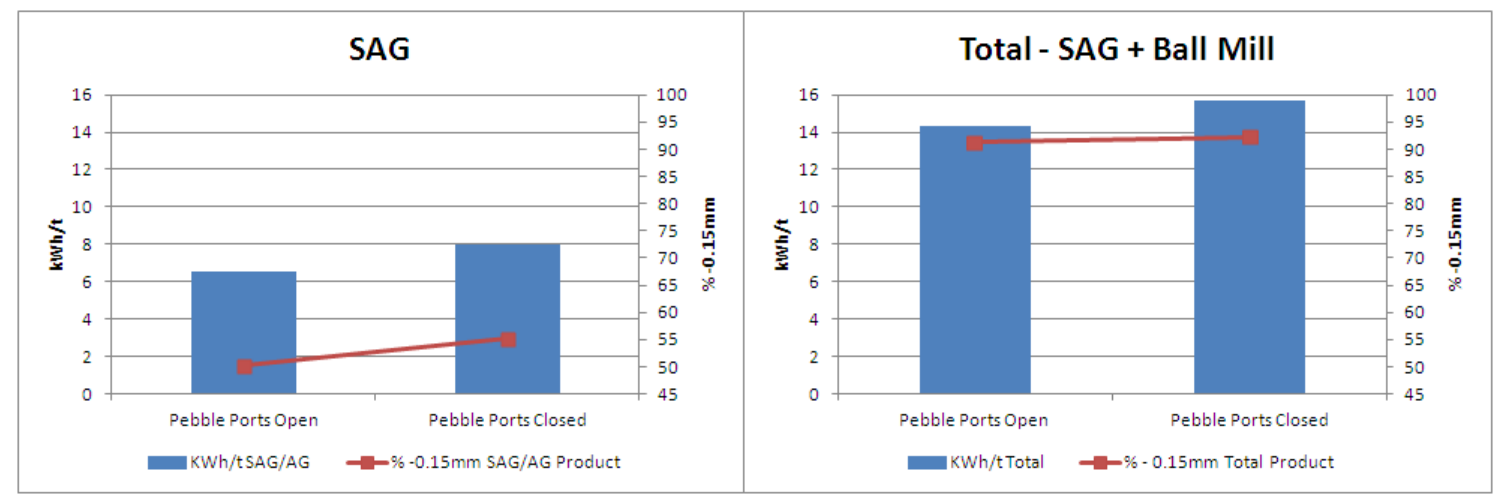

Figura 15 - Efeito do britador de pebbles - Jangada

Como pode ser visto pelas figuras acima, a amostra do Pico requer um baixo consumo especifico de energia, isto permite que o SAG/AG opere com altas vazões de polpa. Entretanto, segundo Sanjeeva Latchireddi [3] existe um volume máximo de polpa antes da formação de piscina. A Figura 16 mostra fotos da carga interna dos testes com a amostra GAL 01 - IC (Pico), através da qual é possível visualizar nos circuitos single stage, no qual o moinho é alimentado pela alimentação nova mais a alta carga circulante, a formação de piscina.

* Contribuição técnica ao 44 Seminário de Redução de Minério de Ferro e Matérias-primas, 15은 Simpósio Brasileiro de Minério de Ferro e 2ํ Simpósio Brasileiro de Aglomeração de Minério de Ferro, 15 a 18 de setembro de 2014, Belo Horizonte, MG, Brasil. 


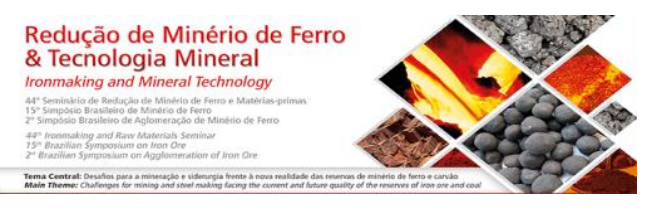

Circuito Aberto

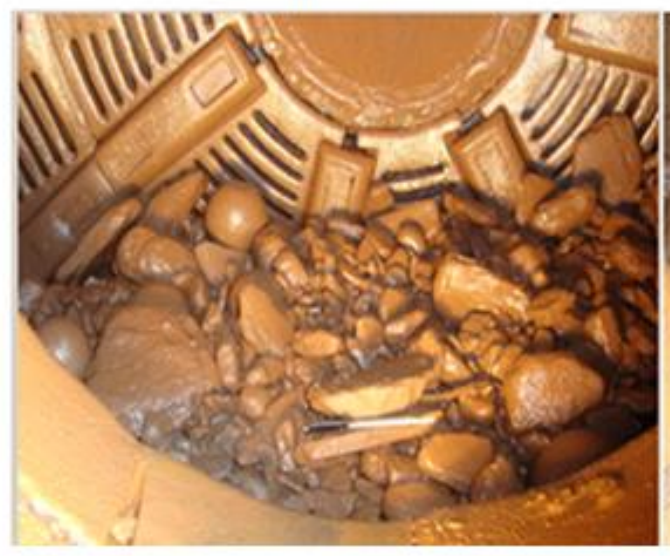

Figura 16 - Fotos das cargas internas dos testes SAG - GAL 01 - IC (Pico)

\subsection{Resultados dos testes em escala de bancada}

A Figura 17 apresenta os resultados de DWT com as amostras piloto e furos de sonda. Através desta figura é possível concluir que existe uma grande variabilidade nos depósitos estudados, e que provavelmente a média do Axb dos dois depósitos estará entre as duas amostras piloto.

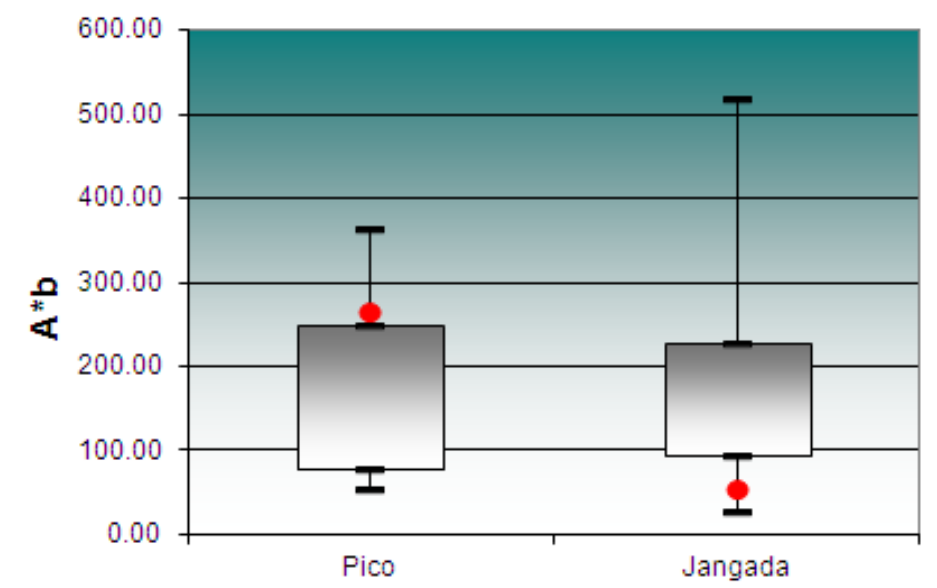

-Valor Máximo dos Furos de Sonda

-Valor de $80 \%$ dos Furos de Sonda

- Valor da Amostra Piloto

- Valor de 20\% dos Furos de Sonda

- Valor Mínimo dos Furos de Sonda

Figura 17 - Resumo dos ensaios de DWT com furos de sonda e amostra piloto

Para comparação foi levantado os dados de Sossego, usina da Vale onde tem um moinho SAG em operação com minério de cobre (Tabela 3). Pode-se observar que 0 minério de cobre é bem mais competente que o minério de ferro testado.

Tabela 3 - Resumo dos resultados dos testes piloto em circuito fechado

\begin{tabular}{cccccc}
\hline Teste & Resultado & Avaliação & Sossego & $\begin{array}{c}\text { Pico } \\
20 \% / 80 \%\end{array}$ & $\begin{array}{c}\text { Jangada } \\
20 \% / 80 \%\end{array}$ \\
\hline $\begin{array}{c}\text { Drop Weight } \\
\text { Test (DWT) }\end{array}$ & $\mathrm{A}^{*} \mathrm{~b}$ & $\begin{array}{c}\text { Quanto menor } \\
\text { mais competente }\end{array}$ & 33 & 79 & 95 \\
\hline $\begin{array}{c}\text { Abrasividade de } \\
\text { Bond }\end{array}$ & $\mathrm{Ai}(\mathrm{g})$ & $\begin{array}{c}\text { Quanto maior } \\
\text { mais abrasivo }\end{array}$ & 0.48 & 0.15 & 0.21 \\
\hline
\end{tabular}

* Contribuição técnica ao 44 Seminário de Redução de Minério de Ferro e Matérias-primas, $15^{\circ}$ Simpósio Brasileiro de Minério de Ferro e $2^{\circ}$ Simpósio Brasileiro de Aglomeração de Minério de Ferro, 15 a 18 de setembro de 2014, Belo Horizonte, MG, Brasil. 


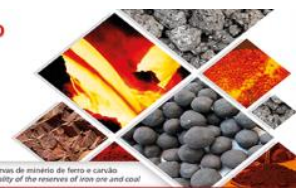

Outra estimativa importante é o consumo de revestimento do SAG. Sabe-se que o consumo de revestimento é diretamente proporcional ao Ai. Para estimativa deste consumo foi levantado dados de duas plantas industriais, sendo que o Ai do Itabirito esta no entre os Ai's destas duas plantas. A Figura 18 apresenta uma correlação entre abrasividade e vida útil de revestimento para duas minas, uma de ouro localizada em Minas Gerais e outra de Cobre em Sossego. Vale ressaltar que foi traçado uma curva em função da equação do Bond [1], na qual ele descreve que o Consumo Revestimento $=0,0118^{\star}(\mathrm{Ai}-0,015)^{\wedge} 0,3$.

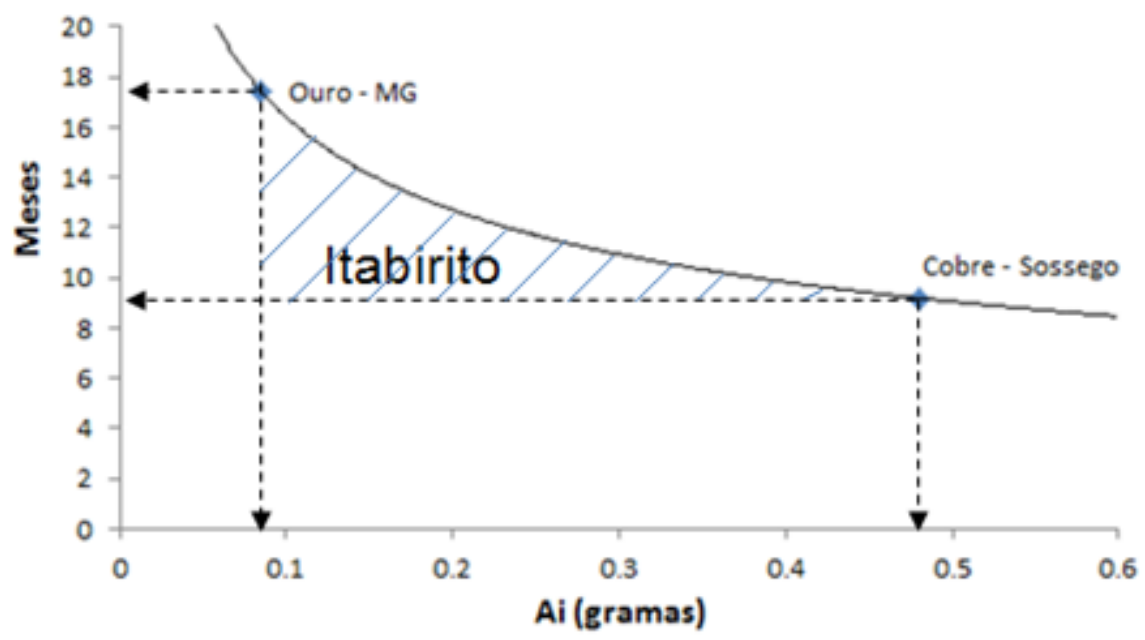

Figura 18 - Vida útil do revestimento do SAG x Abrasividade

\section{CONCLUSÃO}

As seguintes conclusões podem ser retiradas do trabalho:

- Os testes piloto demonstraram que moinhos SAG e AG são apropriados para a cominuição de Itabirito. Apesar do fato de Itabirito normalmente requerer um baixo consumo especifico de energia, seu caráter bimodal permite que este tipo de minério produza quantidade suficiente de partículas competentes ao ponto de ocorrer a moagem autógena ou semi-autógena.

- O Itabirito está fora do range normal de consumo especifico de energia, pois os valores encontrados são muito inferiores em comparação com outros minérios.

- Uma das desvantagens do SAG é a sua grande instabilidade, a qual é altamente influenciada pela variação de granulometria da alimentação (Figura 14).

- Não é recomendado a utilização de circuito single stage para moagem de Itabirito, pois pode ocorrer a formação de piscina o que reduziria a eficiência de moagem.

- A utilização de britador de pebbles não trouxe ganho de consumo energético para o circuito.

- A indústria de minério de ferro tem alta experiência com britagem/peneiramento (circuitos de produção de granulado e sinter feed). Portanto a utilização de SAG será uma tecnologia totalmente nova para esta indústria, o que traz grandes riscos associados, exigindo analise aprofundada para mitigação destes riscos.

* Contribuição técnica ao 44 Seminário de Redução de Minério de Ferro e Matérias-primas, 15ㅇ Simpósio Brasileiro de Minério de Ferro e 2 Simpósio Brasileiro de Aglomeração de Minério de Ferro, 15 a 18 de setembro de 2014, Belo Horizonte, MG, Brasil. 


\section{REFERENCIAS}

1 Bond FC. The third theory of comminution. Mining Engineering. 1952; Transactions of AIME: p.484-494.

2 Bueno M, Lane G. A review of 10 years of AG/SAG pilot trials. In: Proceedings International Autogenous and Semiautogenous Grinding Technology. 2011.

3 Latchireddi SR. Modelling the performance of grates and pulp lifters in autogenous and semi-autogenous mills [Ph.D. thesis]. Australia: University of Queensland; 2002.

4 Lima N, Rodrigues A, Pinto PF, Delboni HJ. Rotas de Cominuição para Itabiritos Pobres do Quadrilátero Ferrífero. In: 14ํㅗำósio Brasileiro de Minério de Ferro; 2013.

5 Morrell S, Man YT. Using Modelling and simulation for the design of full scale ball mill circuits. Minerals Engineering. 1997;10(12):1311-1327.

6 Napier-Munn TJ, Morrell S, Morrison RD, Kojovic T. Rock testing - determining the material-specific breakage function. In: Minerals Comminution Circuits. Their Operation and Optimisation; 1996; p. 49-94.

7 Starkey J, Dobby G. Application of the Minnovex SAG power index at five Canadian SAG plants. Proceedings International Autogenous and Semiautogenous Grinding Technology; 1996.

* Contribuição técnica ao 44ำ Seminário de Redução de Minério de Ferro e Matérias-primas, 15ㅇ Simpósio Brasileiro de Minério de Ferro e $2^{\circ}$ Simpósio Brasileiro de Aglomeração de Minério de Ferro, 15 a 18 de setembro de 2014, Belo Horizonte, MG, Brasil. 